\title{
First draft genome sequence of a strain belonging to the Zoogloea genus and its gene expression in situ
}

\author{
Emilie E. L. Muller ${ }^{1,3+}$, Shaman Narayanasamy ${ }^{1 \dagger}$, Myriam Zeimes ${ }^{1}$, Cédric C. Laczny ${ }^{1,4}$, Laura A. Lebrun ${ }^{1}$, \\ Malte Herold ${ }^{1}$, Nathan D. Hicks' ${ }^{2}$ John D. Gillece ${ }^{2}$, James M. Schupp ${ }^{2}$, Paul Keim² and Paul Wilmes ${ }^{1 *}$
}

\begin{abstract}
The Gram-negative beta-proteobacterium Zoogloea sp. LCSB751 (LMG 29444) was newly isolated from foaming activated sludge of a municipal wastewater treatment plant. Here, we describe its draft genome sequence and annotation together with a general physiological and genomic analysis, as the first sequenced representative of the Zoogloea genus. Moreover, Zoogloea sp. gene expression in its environment is described using metatranscriptomic data obtained from the same treatment plant. The presented genomic and transcriptomic information demonstrate a pronounced capacity of this genus to synthesize poly- $\beta$-hydroxyalkanoate within wastewater.
\end{abstract}

Keywords: Genome assembly, Genomic features, Lipid metabolism, Metatranscriptomics, Poly-hydroxyalkanoate, Wastewater treatement plant

\section{Introduction}

Zoogloea spp. are chemoorganotrophic bacteria often found in organically enriched aquatic environments and are known to be able to accumulate intracellular granules of poly- $\beta$-hydroxyalkanoate [1]. The combination of these two characteristics renders this genus particulary interesting from the perspective of high-value resource production from wastewater [2, 3]. In particular, PHA may be used to synthesize biodegradable bioplastics or chemically transformed into the biofuel hydroxybutyrate methyl ester [2].

The genus name Zoogloea is derived from the Greek term; meaning 'animal glue', which refers to a phenotypic trait that was previously used to differentiate between Zoogloea species and other metabolically similar bacteria [1]. The polysaccharides making up this "zoogloeal matrix" have been proposed to act as a matrix for the adsorption of heavy metals [4].

To date, no genome sequence exists for any of the representative strains of the five presently recognised

\footnotetext{
*Correspondence: paul.wilmes@uni.lu

${ }^{\dagger}$ Equal contributors

${ }^{1}$ Luxembourg Centre for Systems Biomedicine, University of Luxembourg, 7

Avenue des Hauts-Fourneaux, L-4362 Esch-sur-Alzette, Luxembourg

Full list of author information is available at the end of the article
}

Zoogloea species and thus, limited information is available with regards to the genomic potential of the genus. Here we report the genome of a newly isolated Zoogloea sp. strain as a representative of the genus, with a focus on its biotechnological potential in particular for the production of biodiesel or bioplastics. Accordingly, we studied the Zoogloea core metabolism of the genus, particularly on the lipid accumulating properties of Zoogloea sp. LCSB751. Moreover, we integrate metatranscriptomic sequencing data to resolve gene expression of this genus in situ [5, 6]. Finally, we also analyze the clustered regularly interspaced palindromic repeats mediated defence mechanisms of Zoogloea sp. LCSB751 to infer putatively associated bacteriophages [7].

\section{Organism information}

\section{Classification and features}

Zoogloea sp. LCSB751 was isolated from an activated sludge sample collected from the surface of the first anoxic tank of the Schifflange communal wastewater

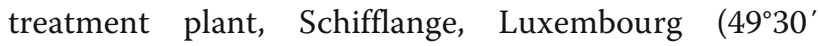
$\left.48.29^{\prime \prime} \mathrm{N} ; 6^{\circ} 1^{\prime} 4.53^{\prime \prime} \mathrm{E}\right)$ on 12 October 2011 . The activated sludge sample was processed by serial dilution with sterile physiological water to a factor of $10^{4}$ and the biomass was then cultivated on solid MSV peptone 
medium [8] at $20{ }^{\circ} \mathrm{C}$ and under anoxic conditions (less than $100 \mathrm{ppm}$ oxygen). Single colonies were iteratively re-plated until a pure culture was obtained. The newly isolated Zoogloea sp. LCSB751 was cryopreserved in 10\% glycerol at $-80{ }^{\circ} \mathrm{C}$.

Zoogloea sp. LCSB751 is a facultative anaerobe as it was found to also grow aerobically at $20{ }^{\circ} \mathrm{C}-25^{\circ} \mathrm{C}$ with agitation in the following liquid media: R2A [9], MSV A + B [8] or Slijkhuis A [10]. Cell clumps were observed in all tested culture conditions. When grown on R2A agar or on MSV peptone agar at $25{ }^{\circ} \mathrm{C}$ under aerobic conditions, Zoogloea sp. LCSB751 colonies were initially punctiform and after three days, they were white, circular and raised with entire edges. The morphology of cells derived from these growth conditions indicates that these are short rod-shaped bacteria (Fig. 1a). The Gram-staining was negative which is in accordance with previously described isolates of Zoogloea spp. [11, 12] (Table 1).

Phylogenetic analysis based on $16 \mathrm{~S}$ rRNA gene sequences confirmed that strain LCSB751 belongs to the Zoogloea genus of the beta-proteobacterial class (Table 1). However, this strain formed a distinct phyletic linage from the five recognized species of Zoogloea, that are represented by the type strains $Z$. caeni $\mathrm{EMB}^{\mathrm{T}} 3^{\mathrm{T}}$ [13], $Z$. oleivorans Buc ${ }^{\mathrm{T}}[11]$, Z. oryzea $\mathrm{A}-7^{\mathrm{T}}$ [14], Z. ramigera Itzigsohn 1868 ATCC $19544^{\mathrm{T}}$ [15] and Z. resiniphila DhA- $35^{\mathrm{T}}[16,17]$ (Fig. 2).

\section{Extended feature descriptions}

The capacity of Zoogloea sp. LCSB751 to accumulate intracellular granules of lipids was tested using the dye Nile Red as described by Roume, Heintz-Buschart et al. [5]. Figure 1b shows the Nile Red positive phenotype of the described strain.

Additionally, the growth characteristics of the strain Zoogloea sp. LCSB751 were determined aerobically and at $25{ }^{\circ} \mathrm{C}$ with agitation in 3 different liquid media. Its generation time was the longest in Slijkhuis A medium with the highest biomass production. MSV A + B allowed a generation time of $4 \mathrm{~h} 30 \mathrm{~min}$ but lead to a poor biomass production as demonstrated by the low maximal optical density at $600 \mathrm{~nm}\left(\mathrm{OD}_{600}\right)$ of 0.21 . The tested liquid medium which allowed the fastest growth for Zoogloea sp. LCSB751 was R2A while the biomass production was close to those observed for Slijkhuis A (Table 2).

\section{Genome sequencing information Genome project history}

Overall, 140 pure bacterial isolates were obtained from a single activated sludge sample, and screened for lipid inclusions using the Nile Red fluorescent dye. The genomes of 85 Nile Red-positive isolates were sequenced, of which isolate LCSB065 has already been published [5]. In particular, the genome of Zoogloea sp. LCSB751 was analyzed to obtain information about the functional potential of this genus, which has no publically available representative genome sequence, but also based on its particular phylogenetic position and to acquire knowledge on the genes related to lipid accumulation. The permanent draft genome sequence of this strain is available on NCBI with the GenBank accession number MWUM00000000 (BioSample: SAMN06480675). Table 3 summarizes the project information according to the MIGS compliance [18].

\section{Growth conditions and genomic DNA preparation}

Zoogloea sp. LCSB751 was grown on MSV peptone agar medium [8] at $20{ }^{\circ} \mathrm{C}$ under anoxic conditions. Half of the biomass was scrapped in order to cryopreserve the strain, while the second half was used for DNA extraction using the Power Soil DNA isolation kit (MO BIO, Carlsbad, CA, USA). This cryostock was used to distribute the strain to the Belgian Coordinated Collection of

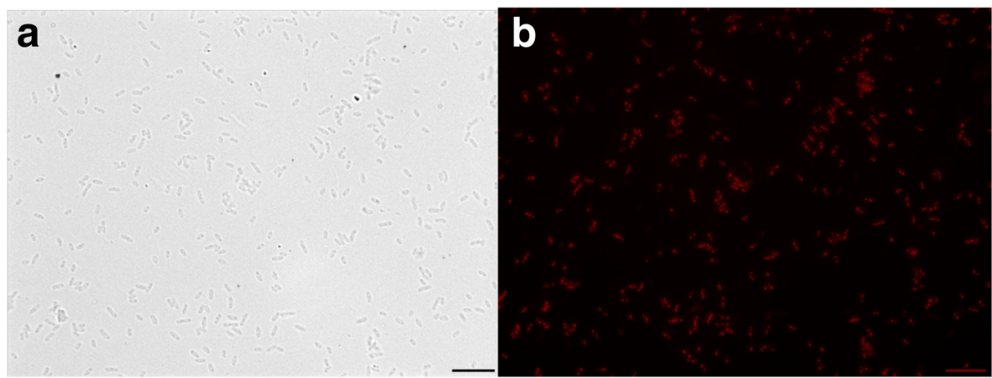

Fig. 1 Photomicrograph of Zoogloea sp. strain LCSB751. a: bright field of anaerobically grown colonies, Nile Red stained after heat fixation; b: same field observed with epifluorescence using an excitation light from a Xenon arc lamp. The beam was passed through an Optoscan monochromator (Cairn Research, Kent, UK) with 550/20 nm selected band pass. Emitted light was reflected through a $620 / 60 \mathrm{~nm}$ bandpass filter with a 565 dichroic connected to a cooled CCD camera (QImaging, Exi Blue). The images were taken using an inverted microscope (Nikon Ti) equipped with a $60 \times$ oil immersion Nikon Apo-Plan lambda objective (1.4 N.A) and an intermediate magnification of $1.5 \times$. The scale represents $10 \mu \mathrm{m}$. All imaging data were collected and analysed using the OptoMorph (Cairn Research, Kent, UK) and ImageJ 
Table 1 Classification and general features of Zoogloea sp. strain LCSB751 according to the MIGS recommendation [18]

\begin{tabular}{|c|c|c|c|}
\hline MIGS ID & Property & Term & Evidence code ${ }^{a}$ \\
\hline & \multirow[t]{8}{*}{ Classification } & Domain Bacteria & TAS [34] \\
\hline & & Phylum Proteobacterium & TAS [35] \\
\hline & & Class Betaproteobacterium & TAS [36] \\
\hline & & Order Rhodocyclales & TAS [13] \\
\hline & & Family Rhodocyclaceae & TAS [13] \\
\hline & & Genus Zoogloea & IDA \\
\hline & & Species Unknown & IDA \\
\hline & & Strain: LCSB751 & \\
\hline & Gram stain & Negative & TAS [1] \\
\hline & Cell shape & Rod & TAS [1] \\
\hline & Motility & Motile & TAS [1] \\
\hline & Sporulation & Not reported & NAS \\
\hline & Temperature range & $5-40{ }^{\circ} \mathrm{C}$ & $\operatorname{TAS}[11,13,14]$ \\
\hline & Optimum temperature & $25-30{ }^{\circ} \mathrm{C}$ & TAS $[11,13]$ \\
\hline & pH range; Optimum & $6.0-9.0 ; 6.5-7.5$ & $\operatorname{TAS}[11,13]$ \\
\hline MIGS-6 & Habitat & Activated sludge & IDA \\
\hline MIGS-6.3 & Salinity & $\begin{array}{l}\text { Inhibited at 0.5\% } \\
\mathrm{NaCl}(w / v)\end{array}$ & TAS [14] \\
\hline MIGS-22 & Oxygen requirement & facultative anaerobe & IDA \\
\hline MIGS-15 & Biotic relationship & free-living & IDA \\
\hline MIGS-14 & Pathogenicity & non-pathogen & NAS \\
\hline MIGS-4 & Geographic location & Luxembourg & IDA \\
\hline MIGS-5 & Sample collection & 2011 & IDA \\
\hline MIGS-4.1 & Latitude & $49^{\circ} 30^{\prime} 48.29^{\prime \prime} \mathrm{N}$ & IDA \\
\hline MIGS-4.2 & Longitude & $6^{\circ} 1^{\prime \prime} 4.53^{\prime \prime} \mathrm{E}$ & IDA \\
\hline MIGS-4.4 & Altitude & $275 \mathrm{~m}$ & IDA \\
\hline
\end{tabular}

avidence codes - IDA Inferred from Direct Assay, TAS Traceable Author Statement (i.e., a direct report exists in the literature), NAS Non-traceable Author Statement (i.e., not directly observed for the living, isolated sample, but based on a generally accepted property for the species, or anecdotal evidence). These evidence codes are from the Gene Ontology project [37]

Microorganisms collection center and deposited under number LMG 29444.

\section{Genome sequencing and assembly}

The purified DNA was sequenced on an Illumina Genome Analyzer IIx as previously described by Roume, Heintz-Buschart and colleagues [5]. Briefly, a paired-end sequencing library with a theoretical insert size of 300 bp was prepared with the AMPure XP/Size Select Buffer Protocol as previously described by Kozarewa \& Turner [19], modified to allow for size-selection of fragments using the double solid phase reversible immobilization procedure [20] and sequenced on an Illumina HiSeq with a read length of $100 \mathrm{bp}$ at TGen North (AZ, USA). The resulting 2,638,115 paired-end reads were trimmed of $\mathrm{N}$ bases (i.e. minimum phred quality score of 3 and filtered for Illumina TruSeq3 adapters), retaining 2,508,729 ( 95\%) of paired reads, 129,378 and eight forward- and reverse-singleton reads (i.e. mate pair discarded), respectively. All reads retained (paired-end and singleton reads) after the pre-processing were de novo assembled using SPAdes ver. 3.1.1, using the default kmer range and parameters [21].

The total number of contigs (776), the mean contig length $(7497 \mathrm{bp})$ and the N50 value $(180,423 \mathrm{bp})$ of the draft assembly of Zoogloea sp. LCSB751 (Table 3) indicate a fragmented assembly despite an estimated sequencing depth of $\sim 150 \times$ fold coverage, $\sim 100 \times$ based on 21-mer frequencies (using KMC2 [22]) and a $\sim 120 \times$ average depth of coverage based on mapping reads back onto the de novo assembled contigs [23-25]. Assembled contigs above $1 \mathrm{~kb}$ are represented in Fig. 3.

\section{Genome annotation}

Gene (i.e. open reading frame) prediction and annotation was carried out on the assembled contigs using Prokka ver. 1.11 [26] and the RAST server [27], both executed using default parameters and databases. Briefly, Prokka predicted a total of 5200 features including 5118 CDS, 3 rRNA, 76 tRNA genes and one tmRNA genes as well as two repeat regions. Similarly, the RAST server predicted a total of 5202 features, of which 5125 represent coding sequences (CDS), 6 rRNA and 71 tRNA genes. The annotation derived from the RAST server was used for most of the genome descriptions and downstream analyses, unless explicitly mentioned. CDS on the forward and reverse strands within contigs above $1 \mathrm{~kb}$ are represented in Fig. 3. In addition, the proteins predicted by the RAST server were submitted to i) the WebMGA server [28], ii) the SignalP server v.4.1 [29] and iii) the TMHMM server v.2.0 [30], for COG functional annotation, signal peptides prediction and transmembrane helices prediction, respectively. 5202 of the predicted amino acid sequences were annotated with 13,030 Pfam IDs. Finally, metaCRT [31] was used to predict CRISPR loci and the resulting CRISPR-spacers were submitted to the CRISPRtarget server [32] for the identification of putatively associated bacteriophage sequences.

\section{Genome properties}

The draft genome assembly of Zoogloea sp. LCSB751 consists of $5,817,831$ bp with a $\mathrm{G}+\mathrm{C}$ content of $64.2 \%$, distributed over 776 contigs (773 scaffolds) with an N50 value of 180,423 bp (Table 4), GC-skew and -deviation of contigs above $1 \mathrm{~kb}$ are represented in Fig. 3. The raw reads are available via the GenBank nucleotide database under the accession number MWUM00000000, while the assembly and the annotation (IDs 6666666.102999) can be accessed through the RAST server guest account.

The rRNA operon region is assumed to be occurring in multiple copies, because all reads from this region 


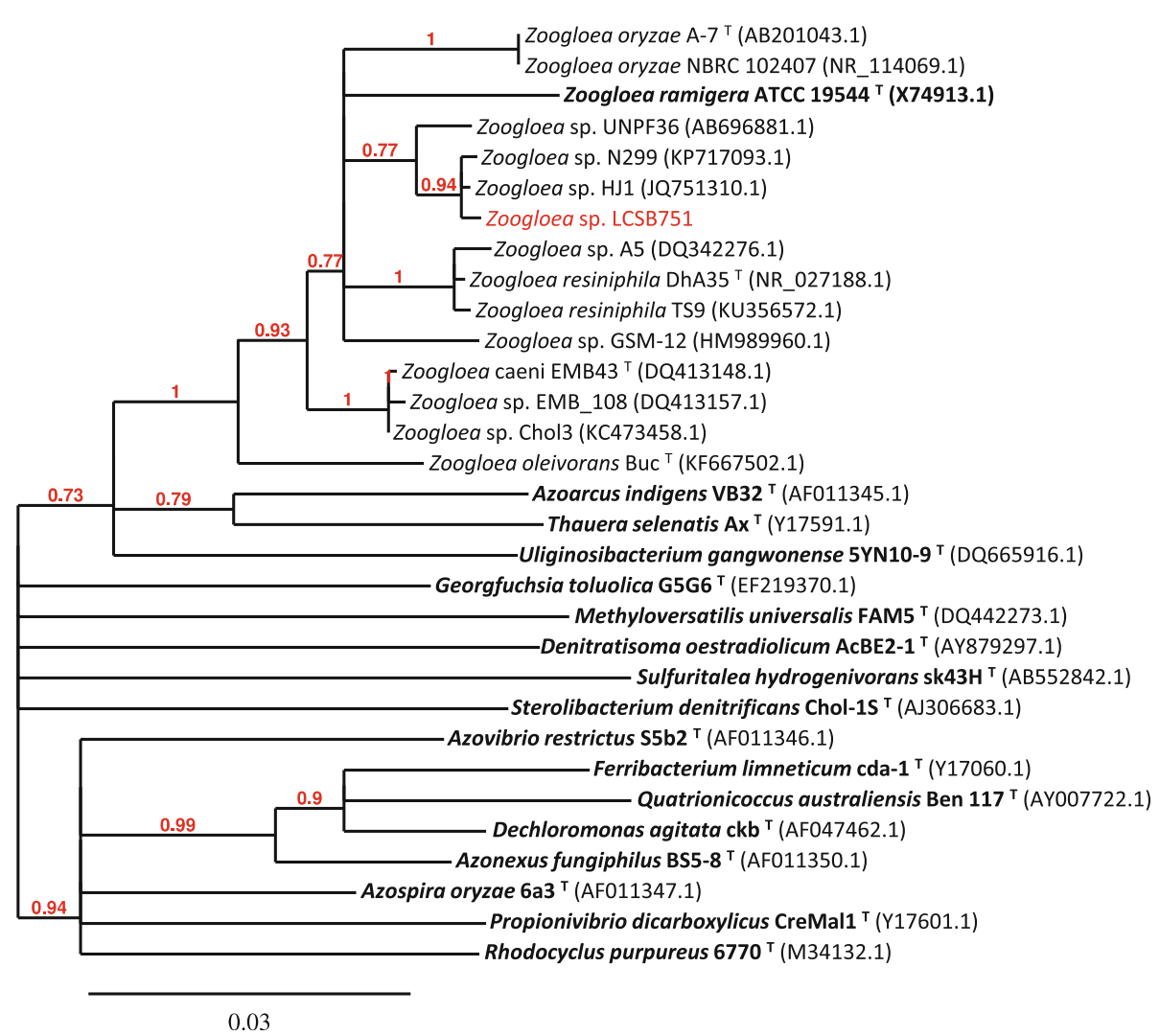

Fig. 2 Phylogenetic tree based on 16S rRNA gene sequences. The type species strains of every species of the Rhodocyclaceae family were used (in bold) as well as all the type strains of the genus Zoogloea, according to the List of Prokaryotic names with Standing in Nomenclature (LPSN; http://www.bacterio.net). Whole genome GenBank IDs are provided in brackets. The $16 \mathrm{~S}$ rRNA sequences were aligned using ClustalW, the alignment was curated using Gblocks conserving $81 \%$ of the initial positions and the phylogeny was computed with BioNJ using 100 bootstraps and the default (K2P) substitution model, using the pipeline Phylogeny.fr [38]

were assembled into a single contig with a higher depth of coverage $(\sim 1200 \times$, for RAST server features: fig|6666666.102999.rna.57, fig|6666666.102999.rna.60 and fig|6666666.102999.rna.61) compared to the rest of the genome. All 20 regular amino-acids were covered by tRNA-anticodons. The RAST server and Prokka annotated approximately 22\% (1139) and 26\% (1329) of the CDS as hypothetical proteins or proteins of unknown function, respectively. The distribution of COG functional

Table 2 Generation time, growth rate and maximum growth of Zoogloea sp. LCSB751 under different aerobic culture conditions

\begin{tabular}{llll}
\hline Medium & $\begin{array}{l}\text { Generation time } \\
\pm \text { standard deviation }\end{array}$ & $\begin{array}{l}\text { Growth rate } \\
\left(\mathrm{min}^{-1}\right)\end{array}$ & Maximum OD \\
\hline R2A & 1 h 54 min \pm 3 min & 0.0058 & 0.46 \\
MSV A + B & 4 h 30 min \pm 53 min & 0.0026 & 0.21 \\
Slijkhuis A & 10 h 42 min \pm 1 h 51 min & 0.0011 & 0.73 \\
\hline
\end{tabular}

${ }^{a}$ Values are an average of independent triplicate experiments

${ }^{\mathrm{b}} \mathrm{OD}_{600}$ stands for optical density measured at $600 \mathrm{~nm}$ with the spectrometer "Biochrom WPA CO 8000 Cell Density Meter" using BRAND disposable semimicro UV cuvettes of $12.5 \times 12.5 \times 45 \mathrm{~mm}$ categories are reported in Table 5, while subsystem-based functional classification are available via RAST server.

\section{Insights from the genome sequence \\ Genome-based inference of the central metabolism}

The genome of Zoogloea sp. LCSB751 is predicted to encode for all the genes required for a complete TCA cycle, but is missing some or the complete set of genes for the EMP pathway, the pentose phosphate pathway and the Entner-Doudoroff pathway.

A periplasmic nitrate reductase as well as a nitrite reductase were identified, suggesting complete reduction of nitrate to ammonia by Zoogloea sp. LCSB751. Furthermore, a complete set of nif genes involved in nitrogen fixation were also encoded in the genome.

Genes for a complete electron transport chain were predicted as well as an alternative RNF complex [33].

The genome of Zoogloea sp. LCSB751 also encodes numerous genes for flagella synthesis and assembly, suggesting a motile lifestyle. Furthermore, the strain is predicted to be prototroph for all amino acids, nucleotides 
Table 3 Project information

\begin{tabular}{|c|c|c|}
\hline MIGS ID & Property & Term \\
\hline MIGS 31 & Finishing quality & Draft \\
\hline MIGS-28 & Libraries used & $\begin{array}{l}\text { Illumina paired-end reads } \\
\text { (insert size } 30 \mathrm{bp} \text { ) }\end{array}$ \\
\hline MIGS 29 & Sequencing platforms & Illumina HiSeq \\
\hline MIGS 31.2 & Fold coverage & $150 \times$ \\
\hline MIGS 30 & Assemblers & SPAdes (version 3.1.1) \\
\hline \multirow[t]{6}{*}{ MIGS 32} & Gene calling method & RAST server ${ }^{a}$ and Prokka ${ }^{b}$ \\
\hline & Locus Tag & fig|6666666.102999 \\
\hline & Genbank ID & MWUM00000000 \\
\hline & GenBank Date of Release & 15 March 2017 \\
\hline & GOLD ID & Gs0128811 \\
\hline & BIOPROJECT & PRJNA230567 \\
\hline \multirow[t]{2}{*}{ MIGS 13} & Source Material Identifier & LMG 29444 \\
\hline & Project relevance & $\begin{array}{l}\text { Environmental, biodiversity, } \\
\text { biotechnological }\end{array}$ \\
\hline
\end{tabular}

${ }^{\mathrm{a}}$ Gene calling using GLIMMER [27, 39]

${ }^{\mathrm{b}}$ Gene calling using Prodigal $[26,40]$ and vitamins $B_{2}, B_{6}, B_{9}, H$, and is missing a single gene for the synthesis of $\mathrm{B}_{12}$.

Additionally, the catechol 2,3-dioxygenase that has been studied in $Z$. oleivorans, was found to be encoded by the genome of Zoogloea sp. LCSB751 [11].

\section{Lipid metabolism}

The genome of Zoogloea sp. LCSB751 was further analysed with a focus on genes related to lipid metabolism, to better understand the lipid accumulation properties of Zoogloea spp. With 202 genes annotated with COG functional category I "Lipid transport and metabolism", more than $3.8 \%$ of the genome of Zoogloea sp. LCSB751 is potentially dedicated to lipid metabolism (Table 5 and Fig. 3). Using the SEED subsystem feature, similar results were obtained with 194 genes (3.8\%) classified in the "Fatty acids, lipids and Isoprenoids" subsystem (Table 6).

Specifically, a complete set of predicted genes necessary for the synthesis, polymerisation and depolymerisation of PHA [2] was found as well as the genes of the MEP/DOXP pathway for terpenoid synthesis. However,

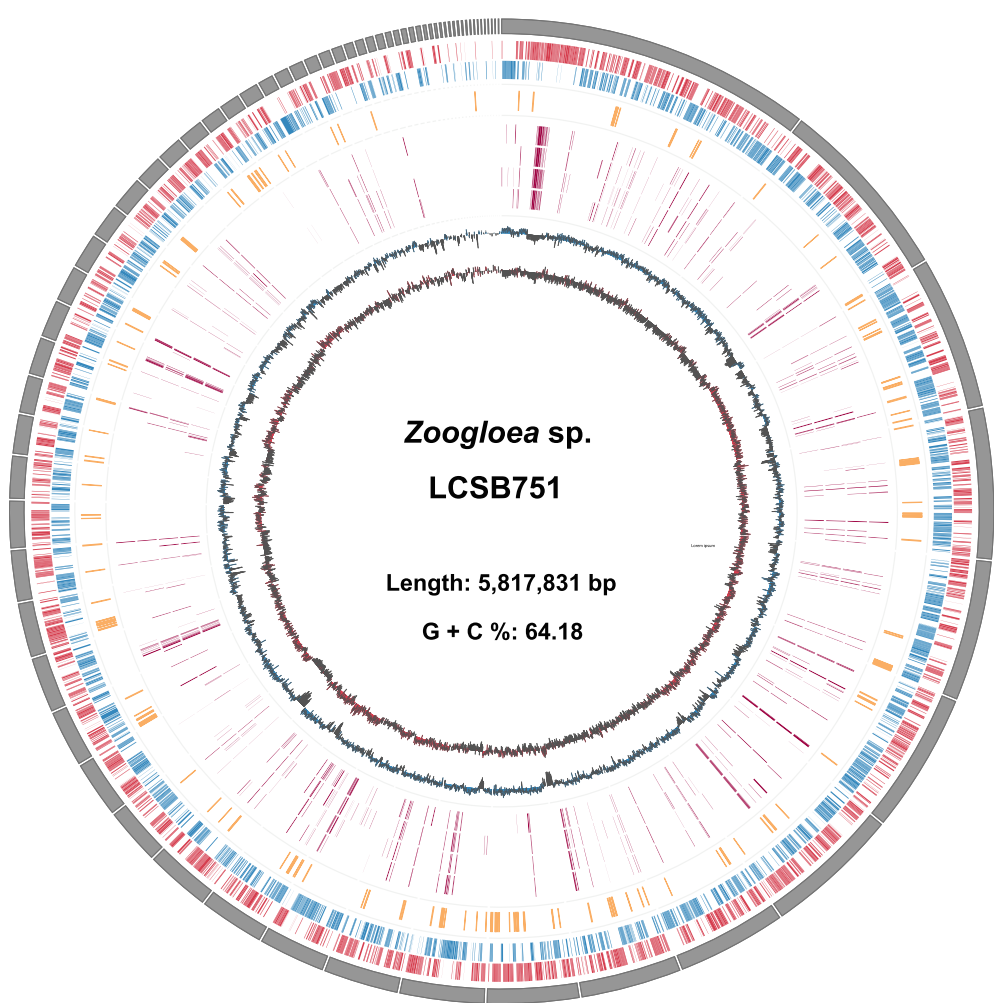

Fig. 3 Circular graphical map of the Zoogloea sp. LCSB751 draft genome assembly, annotation and in situ expression. Data shown on the map explained from the outer to inner circles (i-x): i) contigs above $1 \mathrm{~kb}$. Accordingly, all subsequent information contained within inner circles are based on these contigs, including ii) forward strand coding sequences in red (CDS), iii) reverse strand CDS in blue, iv) CDS that are related to lipid accumulation in yellow (forward and reverse strands), v-viii) gene expression in situ based on metatranscriptomic data from four sampling dates (25 January 2011, 11 January 2012, 5 October 2011, and 12 October 2011 [6]) ix) GC-deviation (from overall G + C \%) and x) GC-skew, respectively. Graphics were generated using Circos [41]. CDS were predicted and annotated using the RAST server [27]. Metatranscriptomic data from four sampling dates were aligned against the draft genome using BWA [42] and depth of coverage, computed using BEDtools [25] was used as a proxy for expression. Depth of coverage $<0.3$ were set to zero 
Table 4 Genome statistics of Zoogloea sp. LCSB751

\begin{tabular}{|c|c|c|}
\hline Attribute & Value & $\%$ of Total $^{a}$ \\
\hline Genome size (bp) & $5,817,831$ & 100.00 \\
\hline DNA coding $(b p)^{b}$ & $4,966,077$ & 85.36 \\
\hline DNA G + C (bp) & $3,733,728$ & 64.18 \\
\hline DNA scaffolds & 773 & 100.00 \\
\hline Total genes & $5,202^{c} / 5,200^{d}$ & $100.00^{c} / 100.00^{d}$ \\
\hline Protein coding genes & $5,125^{c} / 5,118^{d}$ & $98.52^{c} / 98.42^{d}$ \\
\hline RNA genes & $77^{c} / 80^{d}$ & $1.48^{\mathrm{c}} / 1.54^{\mathrm{d}}$ \\
\hline Pseudo genes & unknown & unknown \\
\hline Genes in internal clusters & unknown & unknown \\
\hline Genes with function prediction ${ }^{c}$ & 3661 & 70.38 \\
\hline Genes assigned to COGs & 4191 & 80.56 \\
\hline Genes with Pfam domains & 4202 & 80.78 \\
\hline Genes with signal peptides & 505 & 9.71 \\
\hline Genes with transmembrane helices & 1157 & 22.24 \\
\hline CRISPR repeats & $2^{d} / 3^{e}$ & 2.85 \\
\hline
\end{tabular}

${ }^{\mathrm{a}}$ Total is based on either the size of the genome in base pairs, total number of scaffolds or the total number of genes in the annotated genome

${ }^{b}$ Cumulative length of genes, without considering overlaps

'As predicted by RAST server [27]

${ }^{\mathrm{d}}$ As predicted by Pokka [26]

${ }^{\mathrm{e}}$ As predicted by MetaCRT [31]

the gene necessary to convert diacylglycerol in triacylglycerol or fatty alcohol in wax ester was not predicted, suggesting that PHA granules are the only lipid bodies accumulated in Zoogloea sp. LCSB751.

\section{In situ gene expression}

While genomic data provides information about the genetic potential of Zoogloea sp. LCSB751, it is possible to study expressed functions of the Zoogloea population in situ by using metatranscriptomic data derived from the biological wastewater treatment plant this strain originated from. Metatranscriptomic data derived from samples collected at four distinct time points (25 January 2011, 11 January 2012, 5 October 2011, and 12 October 2011), as studied by Muller and collaborators [6] was used herein. Genes with an average depth of coverage equal or higher than 0.3 were considered as expressed by mapping the rRNA-depleted transcripts on the genome of Zoogloea sp. LCSB751. 259, 312, 269 and 330 genes, respectively, were expressed, with 160 of them being expressed at all four time points (Fig. 3 and Additional file 1: Table S1). For the vast majority, (4732 genes), no transcripts were detected, which can be explained by the low population size of Zoogloea sp. in situ. This was estimated by phylogenetic marker gene (16S rRNA) amplicon sequencing on the sample collected on 25 January 2011 (data from [6]), for which the
Table 5 Number of genes associated with general COG functional categories

\begin{tabular}{|c|c|c|c|}
\hline Code & Value & \%age & Description \\
\hline J & 182 & 3.50 & $\begin{array}{l}\text { Translation, ribosomal structure and } \\
\text { biogenesis }\end{array}$ \\
\hline A & 3 & 0.06 & RNA processing and modification \\
\hline K & 342 & 6.57 & Transcription \\
\hline L & 204 & 3.92 & Replication, recombination and repair \\
\hline B & 3 & 0.06 & Chromatin structure and dynamics \\
\hline D & 52 & 1.00 & $\begin{array}{l}\text { Cell cycle control, Cell division, } \\
\text { chromosome partitioning }\end{array}$ \\
\hline V & 69 & 1.33 & Defense mechanisms \\
\hline $\mathrm{T}$ & 564 & 10.84 & Signal transduction mechanisms \\
\hline M & 252 & 4.84 & Cell wall/membrane biogenesis \\
\hline $\mathrm{N}$ & 177 & 3.40 & Cell motility \\
\hline U & 142 & 2.73 & Intracellular trafficking and secretion \\
\hline O & 189 & 3.63 & $\begin{array}{l}\text { Posttranslational modification, } \\
\text { protein turnover, chaperones }\end{array}$ \\
\hline C & 362 & 6.96 & Energy production and conversion \\
\hline G & 130 & 2.50 & Carbohydrate transport and metabolism \\
\hline E & 305 & 5.86 & Amino acid transport and metabolism \\
\hline $\mathrm{F}$ & 85 & 1.63 & Nucleotide transport and metabolism \\
\hline $\mathrm{H}$ & 185 & 3.56 & Coenzyme transport and metabolism \\
\hline I & 202 & 3.88 & Lipid transport and metabolism \\
\hline$P$ & 283 & 5.44 & Inorganic ion transport and metabolism \\
\hline Q & 126 & 2.42 & $\begin{array}{l}\text { Secondary metabolites biosynthesis, } \\
\text { transport and catabolism }\end{array}$ \\
\hline $\mathrm{R}$ & 520 & 10.00 & General function prediction only \\
\hline S & 351 & 6.75 & Function unknown \\
\hline - & 1011 & 19.43 & Not in COGs \\
\hline
\end{tabular}

Percentage (\%) is based on the total number of protein coding genes in the genome

Zoogloea sp. population size was estimated at $0.1 \%$. Similarly, metagenomic data from all the samples further support the low abundance of this strain in situ (Additional file 1: Table S2).

Nitrate reductase encoding genes (specifically the periplasmic nitrate reductase; NapA) were found to be expressed in all the four time points, while nitrite reductase or nitrogen fixation genes were sporadically expressed in those four time points. Interestingly, at least one copy of the acetoacetyl-CoA reductase and of the polyhydroxyalkanoic acid synthase were found to be expressed at each time point, possibly suggesting PHA accumulation by the population of Zoogloea sp. in this environment. Additionally, the third most expressed gene of Zoogloea sp. in this environment is a "granule associated protein (phasin)" typically known to be associated with PHA granules. 
Table 6 Gene abundance and frequency related to the lipid metabolism of Zoogloea sp. LCSB751

\begin{tabular}{|c|c|c|}
\hline Subsystem & $\begin{array}{l}\text { Subsystem } \\
\text { feature count }\end{array}$ & $\begin{array}{l}\text { Subsystem } \\
\text { feature (\%) }\end{array}$ \\
\hline Fatty acids, lipids and isoprenoids & 194 & 100 \\
\hline Phospholipids & 30 & 15.46 \\
\hline Cardiolipin synthesis & 2 & 6.67 \\
\hline $\begin{array}{l}\text { Glycerolipid and glycerophospholipid } \\
\text { metabolism in bacteria }\end{array}$ & 28 & 93.33 \\
\hline Triacylglycerols & 3 & 1.55 \\
\hline Triacylglycerol metabolism & 3 & 100 \\
\hline Fatty acids & 71 & 36.60 \\
\hline Fatty acid biosynthesis FASII & 30 & 42.25 \\
\hline Fatty acid metabolism cluster & 41 & 57.75 \\
\hline $\begin{array}{l}\text { Fatty acids, lipids and isoprenoids - no } \\
\text { subcategory }\end{array}$ & 56 & 28.87 \\
\hline Polyhydroxybutyrate metabolism & 56 & 100 \\
\hline Isoprenoids & 34 & 17.53 \\
\hline Isoprenoids for quinones & 5 & 14.71 \\
\hline Isoprenoid biosynthesis & 18 & 52.94 \\
\hline Polyprenyl diphosphate biosynthesis & 4 & 11.76 \\
\hline $\begin{array}{l}\text { Nonmevalonate branch of isoprenoid } \\
\text { Biosynthesis }\end{array}$ & 7 & 20.59 \\
\hline
\end{tabular}

The different categories (in bold) and subcategories of the subsystem "Fatty acids, lipids and isoprenoid" are represented

\section{CRISPR-Cas system and putative bacteriophages}

A total of three CRISPR loci were detected with metaCRT, accompanied by six CRISPR-associated (cas) genes. Five of the predicted cas genes occur consecutively, within the same contig and all of the predicted cas genes occur adjacent to a CRISPR locus [7]. Two of CRISPR repeats types were $37 \mathrm{bp}$ in length (sequence: GTTTCAATCCACGTCCGTTAT TGCTAACGGACGAATC; GTGGCACTCGCTCCGA AGGGAGCGACTTCGTTGAAGC) while one of them is 32 bp (sequence: CACTCGCTCCGGAGGGAGC GACTTCGTTGAAG). These CRISPRs contain 175, 51 and 11 spacers, respectively, ranging from lengths of 33 to $46 \mathrm{bp}$. A total of 77 matches were found when searching the spacers against the ACLAME phage/viral/plasmid gene database, NCBI phage and NCBI virus databases using the CRISPRtarget tool [32]. 51 of the spacers match to bacteriophages, 6 to viruses, 11 to genes within plasmids and six to genes within prophages (Additional file 1: Table S3). Based on the available metatranscriptomic data, minute to no expression of the cas genes was observed, while the detected CRISPR regions were not covered by the metatranscriptomic data (Additional file 1: Table S1). This is likely due to the overall low abundance of this species in situ (Additional file 1: Table S2).

\section{Conclusions}

We describe the first draft genome of a strain potentially belonging to a novel species within the genus Zoogloea. The genetic inventory of Zoogloea sp. LCSB751 makes it of particular interest for future wastewater treatment strategies based around the comprehensive reclamation of nutrients and chemical energy-rich biomolecules around the concept of a "wastewater biorefinery column" [3] as well as for industrial biotechnological applications. Future comparative genomics studies would allow the scientific community to further confirm if the reported genomic repertoire is indeed typical of this genus. Using metatranscriptomic data, we further show that Zoogloea sp. populations are active in the studied wastewater treatment plant despite being low in abundance and likely accumulate PHA in situ.

\section{Additional file}

Additional file 1: Table S1. Metatranscriptomic coverage for the predicted features of Zoogloea sp. LCSB751. Table S2. Metagenomic coverage for the assembly contigs of Zoogloea sp. LCSB751. Table S3. Zoogloea sp. LCSB751 CRISPR spacer complements (protospacer) as per reported by CRISPRTarget [32]. (XLSX $182 \mathrm{~kb})$

\section{Abbreviations}

COG: Clusters of Orthologous Groups; CRISPR: Clustered regularly interspaced palindromic repeats; PHA: Poly- $\beta$-hydroxyalkanoate; Cas: CRISPR-associated

\section{Acknowledgements}

The authors thank Mr. Bissen and Mr. Di Pentima from the Syndicat Intercommunal à Vocation Ecologique (SIVEC) for their permission to collect samples and gain access to the monitoring platform of the Schifflange wastewater treatment plant; Dr. Nicolás Pinel for assisting with the large data transfers and initial analysis of the isolates. Dr. Aidos Baumuratov for his support for microscopic analyses of the isolates; and the high performance computing facilities of the University of Luxembourg. This work was supported by an ATTRACT program grant (ATTRACT/A09/03) and a European Union Joint Programming in Neurodegenerative Diseases grant (INTER/ JPND/12/01) both to PW, and Aide à la Formation Recherche (AFR) grants to both EELM (PRD-2011-1/SR) and SN (PHD-2014-1/7934898) as well as a CORE Junior grant to EELM (C15/SR/10404839), all funded by the Luxembourg National Research Fund (FNR).

\section{Authors' contributions}

EELM and LAL isolated the strain, LAL prepared the DNA, NDH prepared the library and sequenced it, SN, MZ, CCL and EELM performed the bioinformatics analyses. MZ performed growth experiments. $\mathrm{MH}$ and EELM visualized data. EELM and PW designed and coordinated the project. All authors read and approved the final manuscript.

\section{Competing interests}

The authors declare that they have no competing interests.

\section{Publisher's Note}

Springer Nature remains neutral with regard to jurisdictional claims in published maps and institutional affiliations.

\section{Author details}

'Luxembourg Centre for Systems Biomedicine, University of Luxembourg, 7 Avenue des Hauts-Fourneaux, L-4362 Esch-sur-Alzette, Luxembourg. ${ }^{2}$ TGen North, 3051 West Shamrell Boulevard, Flagstaff, AZ 86001, USA. ${ }^{3}$ Present address: Department of Microbiology, Genomics and the Environment, UMR 
7156 UNISTRA - CNRS, Université de Strasbourg, Strasbourg, France. ${ }^{4}$ Present address: Saarland University, Building E2 1, 66123 Saarbrücken, Germany.

\section{Received: 11 April 2017 Accepted: 21 September 2017 Published online: 18 October 2017}

\section{References}

1. Dugan PR, Stoner DL, Pickrum HM: The Genus Zoogloea. In The Prokaryotes: Vol. 7: Proteobacteria: Delta and Epsilon Subclasses. Deeply Rooting Bacteria. New York: Springer Science \& Business Media; 2006:1105.

2. Muller EEL, Sheik AR, Wilmes P. Lipid-based biofuel production from wastewater. Curr Opin Biotechnol. 2014;30C:9-16.

3. Sheik AR, Muller EEL, Wilmes P. A hundred years of activated sludge: time for a rethink. Front Microbiol. 2014;5(March):47.

4. Sag̃ $Y$, Kutsal T. Biosorption of heavy metals by Zoogloea ramigera: use of adsorption isotherms and a comparison of biosorption characteristics. Chem Eng J Biochem Eng J. 1995;60:181-8.

5. Roume H, Heintz-Buschart A, Muller EEL, May P, Satagopam VP, Laczny CC, Narayanasamy S, Lebrun LA, Hoopmann MR, Schupp JM, Gillece JD, Hicks ND, Engelthaler DM, Sauter T, Keim PS, Moritz RL, Wilmes P. Comparative integrated omics: identification of key functionalities in microbial communitywide metabolic networks. NPJ Biofilms Microbiomes. 2015;1:15007.

6. Muller EEL, Pinel N, Laczny CC, Hoopman MR, Narayanasamy S, Lebrun LA, Roume H, Lin J, May P, Hicks ND, Heintz-Buschart A, Wampach L, Liu CM, Price LB, Gillece JD, Guignard C, Schupp JM, Vlassis N, Baliga NS, Moritz RL, Keim PS, Wilmes P. Community integrated omics links the dominance of a microbial generalist to fine-tuned resource usage. Nat Commun. 2014:5:5603.

7. Amitai G, Sorek R. CRISPR-Cas adaptation: insights into the mechanism of action. Nat Rev Microbiol. 2016;14:67-76.

8. Levantesi C, Rossetti S, Thelen K, Kragelund C, Krooneman J, Eikelboom D, Nielsen PH, Tandoi V. Phylogeny, physiology and distribution of "Candidatus Microthrix calida", a new Microthrix species isolated from industrial activated sludge wastewater treatment plants. Environ Microbiol. 2006;8:1552-63.

9. Reasoner DJ, Geldreich EE. A new medium for the enumeration and subculture of bacteria from potable water. Appl Environ Microbiol. 1985:49:1-7.

10. Slijkhuis H. Microthrix parvicella, a filamentous bacterium isolated from activated sludge: cultivation in a chemically defined medium. Appl Environ Microbiol. 1983:46:832-9.

11. Farkas M, Táncsics A, Kriszt B, Benedek T, Tóth EM, Kéki Z, Veres PG Szoboszlay S. Zoogloea oleivorans sp. nov., a floc-forming, petroleum hydrocarbon-degrading bacterium isolated from biofilm. Int J Syst Evol Microbiol. 2015;65:274-9.

12. Huang T-L, Zhou S-L, Zhang H-H, Bai S-Y, He X-X, Yang X. Nitrogen removal characteristics of a newly isolated indigenous aerobic denitrifier from oligotrophic drinking water reservoir, Zoogloea sp. N299. Int J Mol Sci. 2015:16:10038-60

13. Shao Y, Chung BS, Lee SS, Park W, Lee S-S, Jeon CO. Zoogloea caeni sp. nov. a floc-forming bacterium isolated from activated sludge. Int I Syst Evol Microbiol. 2009;59(Pt 3):526-30

14. Xie C-H, Yokota A. Zoogloea oryzae sp. nov., a nitrogen-fixing bacterium isolated from rice paddy soil, and reclassification of the strain ATCC 19623 as Crabtreella saccharophila gen. nov., sp. nov. Int J Syst Evol Microbiol. 2006;56(Pt 3):619-24.

15. Unz R. Neotype strain of Zoogloea ramigera Itzigsohn. Int J Syst Bacteriol. 1971;21:91-9.

16. Mohn WW, Wilson AE, Bicho P, Moore ER. Physiological and phylogenetic diversity of bacteria growing on resin acids. Syst Appl Microbiol. 1999;22:68-78.

17. International Journal of Systematic Bacteriology. Validation of the publication of new names and new combinations previously effectively published outside the IJSB. List No. 70. Int J Syst Bacteriol 1999, 49:935-936.

18. Field D, Garrity G, Gray T, Morrison N, Selengut J, Sterk P, Tatusova T, Thomson N, Allen MJ, Angiuoli SV, Ashburner M, Axelrod N, Baldauf S, Ballard S, Boore J, Cochrane G, Cole J, Dawyndt P, De Vos P, DePamphilis C, Edwards R, Faruque N, Feldman R, Gilbert J, Gilna P, Glöckner FO, Goldstein P, Guralnick R, Haft D, Hancock D, et al. The minimum information about a genome sequence (MIGS) specification. Nat Biotechnol. 2008;26:541-7.

19. Kozarewa I, Turner DJ.96-plex molecular barcoding for the Illumina Genome Analyzer. Methods Mol Biol. 2011;733:279-98.
20. Rodrigue S, Materna AC, Timberlake SC, Blackburn MC, Malmstrom RR, Alm EJ, Chisholm SW. Unlocking short read sequencing for metagenomics. PLoS One. 2010;5:e11840.

21. Bankevich A, Nurk S, Antipov D, Gurevich AA, Dvorkin M, Kulikov AS, Lesin VM, Nikolenko SI, Pham S, Prijbelski AD, Pyshkin AV, Sirotkin AV, Vyahhi N, Tesler G, Alekseyev MA, Pevzner PA. SPAdes: a new genome assembly algorithm and its applications to single-cell sequencing. J Comput Biol A J Comput Mol Cell Biol. 2012;19:455-77.

22. Deorowicz S, Kokot M, Grabowski S, Debudaj-Grabysz A. KMC 2: fast and resource-frugal k-mer counting. Bioinformatics. 2015;31:1569-76.

23. Li H, Handsaker B, Wysoker A, Fennell T, Ruan J, Homer N, Marth G, Abecasis $G$, Durbin R. The sequence alignment/map format and SAMtools. Bioinformatics. 2009;25:2078-9.

24. Li H, Durbin R. Fast and accurate long-read alignment with BurrowsWheeler transform. Bioinformatics. 2010;26:589-95.

25. Quinlan AR, Hall IM. BEDTools: a flexible suite of utilities for comparing genomic features. Bioinformatics. 2010;26:841-2.

26. Seemann T. Prokka: rapid prokaryotic genome annotation. Bioinformatics. 2014;30:2068-9

27. Aziz RKK, Bartels D, Best AAA, Dejongh M, Disz T, Edwards RAA, Formsma $K$, Gerdes S, Glass EMM, Kubal M, Meyer F, Olsen GJj, Olson R, Osterman ALL, Overbeek RAA, McNeil LKK, Paarmann D, Paczian T, Parrello B, Pusch GDD, Reich C, Stevens R, Vassieva O, Vonstein V, Wilke A, Zagnitko O. The RAST Server: rapid annotations using subsystems technology. BMC Genomics. 2008;9:75

28. Wu S, Zhu Z, Fu L, Niu B, Li W. WebMGA: a customizable web server for fast metagenomic sequence analysis. BMC Genomics. 2011;12:444.

29. Petersen TN, Brunak S, von Heijne G, Nielsen H. SignalP 4.0: discriminating signal peptides from transmembrane regions. Nat Methods. 2011;8:785-6.

30. Krogh A, Larsson B, von Heijne G, Sonnhammer EL. Predicting transmembrane protein topology with a hidden Markov model: application to complete genomes. J Mol Biol. 2001;305:567-80.

31. Bland C, Ramsey TL, Sabree F, Lowe M, Brown K, Kyrpides NC, Hugenholtz P. CRISPR recognition tool (CRT): a tool for automatic detection of clustered regularly interspaced palindromic repeats. BMC Bioinformatics. 2007:8:209.

32. Biswas A, Gagnon JN, Brouns SJJ, Fineran PC, Brown CM. CRISPRTarget. RNA Biol. 2013:10:817-27.

33. Biegel E, Schmidt S, González JM, Müller V. Biochemistry, evolution and physiological function of the Rnf complex, a novel ion-motive electron transport complex in prokaryotes. Cell Mol Life Sci C. 2011;68:613-34.

34. Woese CR, Kandler O, Wheelis ML. Towards a natural system of organisms: proposal for the domains Archaea, Bacteria, and Eucarya. Proc Natl Acad Sci U S A. 1990;87:4576-9.

35. Garrity GM, Bell JA, Lilburn T. Phylum XIV. phyl. nov. In: DJ Brenner, NR Krieg, JT Staley, GM Garrity (eds), Bergey's Manual of Systematic Bacteriology. Second Edition, Volume 2, Part B. New York: Springer; 2005, p. 1.

36. Garrity GM, Bell JA, Lilburn T. Class II. class. nov. In: DJ Brenner, NR Krieg, JT Staley, GM Garrity (eds), Bergey's Manual of Systematic Bacteriology. Second Edition, Volume 2, Part C. New York: Springer; 2005, p. 575.

37. Ashburner M, Ball CA, Blake JA, Botstein D, Butler H, Cherry JM, Davis AP, Dolinski K, Dwight SS, Eppig JT, Harris MA, Hill DP, Issel-Tarver L, Kasarskis A, Lewis S, Matese JC, Richardson JE, Ringwald M, Rubin GM, Sherlock G. Gene ontology: tool for the unification of biology. The Gene Ontology Consortium. Nat Genet. 2000;25:25-9.

38. Dereeper A, Guignon V, Blanc G, Audic S, Buffet S, Chevenet F, Dufayard J-F, Guindon S, Lefort V, Lescot M, Claverie J-M, Gascuel O. Phylogeny.fr: robust phylogenetic analysis for the non-specialist. Nucleic Acids Res. 2008;36(Web Server issue):W465-9.

39. Delcher AL, Harmon D, Kasif S, White O, Salzberg SL. Improved microbia gene identification with GLIMMER. Nucleic Acids Res. 1999;27:4636-41.

40. Hyatt D, Chen G-L, LoCascio PF, Land ML, Larimer FW, Hauser LJ. Prodigal: prokaryotic gene recognition and translation initiation site identification. BMC Bioinformatics. 2010;11:119.

41. Krzywinski M, Schein J, Birol I, Connors J, Gascoyne R, Horsman D, Jones SJ, Marra MA. Circos: an information aesthetic for comparative genomics. Genome Res. 2009:19:1639-45.

42. Li H, Durbin R. Fast and accurate short read alignment with Burrows-Wheeler transform. Bioinformatics. 2009;25:589-95. 